International Journal of Instruction e-ISSN: 1308-1470 • www.e-iji.net

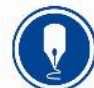

October $2021 \bullet$ Vol.14, No.4

p-ISSN: 1694-609X

pp. 1047-1064

Article submission code

20200915090918

Received: 15/09/2020

Revision: 20/05/2021
Accepted: 17/06/2021

OnlineFirst: 20/09/2021

\title{
Self-efficacy as a Personality Predictor of the Career Orientations of College Students
}

\section{Svetlana Kotova}

Dr., Department of Educational Psychology and Professional Development, Russian state vocational and pedagogical University, Russia, kotovasv76@ rambler.ru

\section{Irina Hasanova}

Dr., Department of Educational Psychology and Professional Development, Russian state vocational and pedagogical University, Russia, hasanovair02@ rambler.ru

\section{Nadia Sadovnikova}

Dr., Department of Professional Pedagogy and Psychology, Russian state vocational and pedagogical University, Russia, sadovnikovana48@ rambler.ru

\section{Evgeny Komarov}

Mr., Department of Educational Psychology and Professional Development, Russian state vocational and pedagogical University, Russia, komarovev59@ rambler.ru

\section{Liu Wenbin}

Mr., Department of Russian and Foreign Languages, Russian state vocational and pedagogical University, Russia, wenbinli93@rambler.ru

In the context of the modern dynamic socio-economic environment, career-related issues are becoming relevant to psychological and pedagogical sciences as it is professional development that enables people to realize their abilities, capabilities, and needs. Career orientation should be identified as early as possible in order to obtain significant achievements. An important issue is related to career orientation predictors, which determine future achievements and career choice. The study discusses conceptual provisions and methodological approaches to assessing the career orientations of college students with different levels of self-efficacy. The purpose of the research is to study theoretical and methodological approaches and aspects of the psychological assessment of self-efficacy as a personality predictor of the career orientations of college students. The study was conducted with the participation of a representative sample of 558 third-year students aged 18 to 20 on the campus of the Ural State College named after I. Polzunov (Ekaterinburg) (average age is 18.7 years). he practical significance of the study arises from the possibility to use the results obtained in order to implement programs aimed at improving self-efficacy in adolescents. The research is of practical value for organizational psychologists, educational psychologists, and teachers.

Keywords: career orientation, personality predictors, college, self-efficacy, students

Citation: Kotova, S., Hasanova, I., Sadovnikova, N., Komarov, E., \& Wenbin, L. (2021). Self-efficacy as a personality predictor of the career orientations of college students. International Journal of Instruction, 14(4), 1047-1064. https://doi.org/10.29333/iji.2021.14460a 


\section{INTRODUCTION}

Conscious career planning is one of the most important aspects of professional development and self-actualization of a person. In the modern socio-economic context, the interaction of a person and a profession is being complicated, which determines the increasing importance of one's own efforts and qualifications (Akosah-Twumasi et al., 2018; Maree, 2017).

At the stage of vocational training, career orientations act as a system of behavioral relations in the course of the self-actualization and the development of professional orientations of the individual. In the course of professionalization, mental processes and states are improved; personal qualities needed for future activities, as well as social and professional competencies are developed; the attitudes are shaped, and life and professional plans are elaborated (Evplova, 2019; Li et al., 2019).

The most important career path component is the idea of one's own personality in the process of professional self-actualization, which involves the so-called professional "Iconcept" that is implemented through a series of career decisions. According to a number of researchers, self-efficacy is one of the factors reflecting the effect of selfawareness on career success (Garanina et al., 2019; Koch \& Orlov, 2020). Self-efficacy is defined as a generalized and relatively constant personal characteristic that allows a person to forecast their success in all spheres of life (Panadero et al., 2017).

The concept of self-efficacy has been discussed in numerous studies (Bandura \& Hall, 2018; Lippke, 2020; Olivier et al., 2019). Due to the extensive and diverse scope of the research on self-efficacy, the studies being conducted are focused on the factorial analysis of the issue and explore its application in different contexts (Peiffer et al., 2020).

There are groups of studies have presented rich evidences of the mediating role of selfefficacy in building of framework of self-management and coping with various types of problems (Ebner et al., 2018). Self-management is an important part of career orientation, the role of which is supported by research (Komarraju et al., 2014; Lent et al., 2017). Self-management is especially important for entrepreneurship, engineering professions, management and other fields of activity (Akosah-Twumasi et al., 2018). Establishing relevant correlations between indicators of self-management and selfefficacy will make it possible to more accurately determine career orientation and predict the professional trajectory of a future specialist, and improve his training.

In the context of forecasting the future and designing individualized paths of lifelong learning and career development, the issue of personality predictors of the career orientations of college students and their correlation with self-efficacy is becoming relevant (Peiffer et al., 2020; Setiawati et al., 2017). Certain predictors or career motivation factors have been studied within the context of parental choice, especially in more conventional societies or families characterized by parental dominance (Suryadi, 2020). In addition to personal factors, the influence of the market, economic motivations and student aspirations for a certain social level and consumption opportunities are considered. This analysis is rather typical for behaviorism advocates (Cybal-Michalska, 2016). 
A number of researchers have considered the career orientations of a person in one aspect or another (Li et al., 2019; Peiffer et al., 2020; Schein \& Schein, 2018).

Today the research focus is placed on the choice of a career model, professional adaptation, career readiness skills, career mobility factors, and career behavior types.

The purpose of the research is to study self-efficacy as a personality predictor of the career orientations of college students. The analytical hypothesis is as follows:

1) There are no significant differences between the career orientations of students with different levels of self-efficacy;

2) There is no possible correlation between career orientations and self-efficacy.

The practical significance of the research arises from the possibility to use the results obtained in order to design and implement programs aimed at improving self-efficacy and the development of career orientations in students in the process of educational and professional activities.

\section{Literature Review}

The problem of self-efficacy and the effective interaction of a person with the environment arose in the theories of professional development many years ago (Lippke, 2020). According to most Western researchers, self-efficacy involves proactivity, responsibility, the ability to independently take responsibility as opposed to accepting it from external sources within the social structure (Cybal-Michalska, 2016). The metaanalysis of the concept shows that it is closely related to self-esteem and the ability to switch off from social pressure while maintaining high involvement in social interaction, as well as to critical thinking and the ability to make independent decisions. The most important self-efficacy factor is the desire to learn and participate in information flows (Panadero et al., 2017).

Russian researchers define self-efficacy as personal beliefs related to one's own ability to manage events that can affect one's own life (Bandura \& Hall, 2018). This definition describes self-efficacy as a high assessment of one's own competence and effectiveness, which differs from self-respect and self-esteem. Leontyev notes that the belief in one's own effectiveness is the most important subjectivity mechanism. People do not want to act when they are not convinced that their actions can produce the desired effect (Leontyev, 2016) Thus, self-efficacy is closely related to motivation mechanisms, in particular, in the context of career choice and development; this is confirmed by Western researchers (Komarraju et al., 2014; Li et al., 2019; Suryadi, 2020).

According to a number of scientists, self-efficacy is the belief of people that they can mobilize motivation, intellectual resources, and behavioral efforts to control events that affect their lives (Schein \& Schein, 2018). Researchers emphasize the effect of selfefficacy on the ability to create communication and professional networks, as well as to change the situation by means of interpersonal communication (Lepri et al., 2016; Maree, 2017). Some studies indicate that self-efficacy and the ability to shape one's own future are closely related to or reflected through some specific skills and activities, such as the ability to take notes and plan (Salame \& Thompson, 2020). 
A group of American psychologists have identified two basic types of self-efficacy, namely professional self-efficacy and verbal self-efficacy (Lippke, 2020). Let us consider them in more detail:

1) professional self-efficacy is related to the belief and confidence of the person that they can apply their knowledge, abilities, skills, and experience previously gained in a particular type of activity to deal with similar situation in the future and achieve success (Lippke, 2020; Olivier et al., 2019; Peiffer et al., 2020);

2) verbal self-efficacy involves the belief of the person that they possess communication skills and the confidence that they can be successful communicators constructively solving communication problems (Lippke, 2020).

Researchers generally agree that the beliefs of a person in their ability to produce desired effects play an important role in achieving success in any activity type (Li et al., 2019; Maree, 2017; Peiffer et al., 2020). We believe that success cannot be achieved unless self-efficacy is sufficiently developed. The semantic components of self-efficacy are reflexivity and mindfulness; productivity and focus on success; manageability and consistency; self-esteem; mobility and flexibility (Olivier et al., 2019).

Therefore, it can be concluded that the self-efficacy components are important not only for personal but also for professional development that can be based on career ideas, interests, and orientations of students.

Acording to Schein and Schein (2018), career orientation (job attitude) arises in the process of socialization and the acquisition and accumulation of professional experience. At the same time, the researchers highlight a significant correlation between the career orientation and career development; they argue that it is the job attitude that is the most important factor in managing an individual career that gives it originality, individuality and uniqueness. Schein and Maanen, Panadero and other researchers believe that career planning and goal-setting are primarily based on a certain hierarchy of "career anchors" that the person has in their mind. Career orientations are not as certain as properly developed career goals and plans (Schein \& Maanen, 2013). As a result, they perform a more flexible regulatory function (Panadero et al., 2017; Schein \& Maanen, 2013).

The intensity and sequence of career orientations are shaped over the years and can change in accordance with the circumstances of the social environment and individual changes (Johnson et al., 2018; Zhu et al., 2019). Consequently, career orientations are one of the personality factors that have a significant impact on career development.

Thus, career orientations are a stable element in the personality structure that is developed at the initial stage of professional life, and, therefore, at university or at the stage of early communication with parents and the formation of personal choice (Suryadi, 2020).

The stages of transformation of individual career orientations and personality attitudes, identified by researchers in recent years, are of great interest to us. Thus, they indicate 
that a career is a flexible concept and depends on the vision and awareness of the individual, as well as the readiness to create one's own development trajectory in the digital space (Bravo et al., 2017).

The analysis of the stages of career orientations transformations allows to conclude that they substantively include the most significant self-efficacy components and the possibility of their implementation in professional activity and communication (Bravo et al., 2017; Cybal-Michalska, 2016). Thus, self-efficacy is a personal predictor of the implementation of career orientations.

Based on this fact, modern foreign researchers are studying the relationship between career orientations of students and personal qualities, such as resoluteness when making career-related decisions; identify difficulties associated with career decisions, and consider strategies to deal with career indecision at the stage of professional adaptation (Li et al., 2019).

The concept of career self-efficacy is described as person's perceived ability to structure and perform actions needed for the implementation of the career plan (Falco \& Summers, 2019). Career self-efficacy affects the behavior of the person when facing obstacles to achieving career goals; it determines the efforts and persistence needed, as well as affects thoughts and emotions of the person (Falco \& Summers, 2019; Zhu et al., 2019). The existing career orientation studies mentioned in this section analyse the individual factors and forces that influence personality formation and the choice of a professional path of development. However, there is a significant gap in evidence-based researches on career choice predictors. Uniquely defined predictors could aid career guidance and student development. This gap seeks to close partially this study.

In this regard, it seems to us that career self-efficacy is an important social and professional competence of the specialist personality that should be developed when studying at an educational institution.

\section{METHOD}

\section{Research methods}

In the course of the research, methods of observation, conversation, analysis of the products of activity, content analysis of essays, self-report, as well as diagnostic methods were used:

1) The self-efficacy test developed by James E. Maddux and D. Scheer (modified by L. Boyarintseva under the guidance of R. Krichevskiy) is one of the methods for studying self-awareness and self-esteem of the person (Boyarintseva, 2003). This is the evaluation of one's own potential in the sphere of substantive activity and communication, which can be implemented. The idea of self-efficacy that the methodology is based on provides an opportunity to obtain not only information on the self-esteem of the person and the degree of self-actualization, but also creates a certain impulse for self-development. Thus, the methodology operationalizes the attempts of the person to become successful in substantive work and interpersonal communication.

2) The Career Anchor methodology (Schein \& Maanen, 2013) is designed to determine 
the leading career orientation, professional motives, value orientations, and social attitudes of the employee according to the scales described below.

3) The self-attitude questionnaire (Stolin \& Pantileev, 1988) is based on the hierarchical model of the structure of self-attitude developed by Stolin. This version of the questionnaire specifies three levels of self-attitude that differ in their degree of generalization: global self-attitude; self-attitude differentiated by self-respect, selfacceptance, self-interest, and expectations of the attitude towards oneself; the level of specific actions (readiness for them) in relation to one's own self.

These methods were chosen due to the experience of their use, due to the fact that they include self-efficacy as one of the important indicators of career orientation, which is consistent with the content of our study.

The validity of both research questionnaires has been confirmed by a significant number of studies and a long-term practice of observing and comparing the results after conducting statistical studies in Russia and a number of other countries. Methods contain a description of validity and reliability tests carried out by their creators in the cited primary sources for these types of tests. In addition, the reliability of the tests has verified by the Cronbach Alpha method by the authors of the article on the test results obtained for the current study. For test 1) $\alpha=0.79$; for test 2), $\alpha=0.83$, for test 3 ) $\alpha=$ 0.81 , which even exceeds the results obtained when testing by the authors of the questionnaires.

The difference between the image of one's own self (knowledge or perception of oneself, including the assessment of the degree of certain traits) and self-attitude is taken as the initial basis. In the course of life, the person becomes acquainted with their own self and accumulates knowledge related to it.

\section{Experimental research base}

The Institute of Psychological and Pedagogical Education of the Russian State Vocational and Pedagogical University conducted this empirical study to determine the level of self-efficacy as a personal predictor of the career orientations of college students; the experiment lasted from December to June 2019.

\section{Participants and data collection}

A total of 558 students of the Ural State College named after I. Polzunov (Ekaterinburg) participated in the study. The experiment involved third-year on-campus students aged 18 to 20 (average age is 18.7 years) studying technical and humanitarian disciplines. The sample has formed by the method of random sampling in order to achieve its representativeness. The sample contains 287 women and 271 men; differentiation by sex, age, social status, origin and other parameters is not significant for the purposes of the study. The general population is 4,452 students; the probable sampling error does not exceed $p=3.88$. The sample can be considered representative.

According to the study hypotheses, the sample divided into the following two groups, based on the self-efficacy test results (see test 1) above in Research methods). Group 1 
that involved respondents with an average level of self-efficacy in the sphere of substantive work and interpersonal communication; Group 2 consisted of respondents who showed a low level of self-efficacy in the sphere of substantive work and interpersonal communication.

The study is based on the questionnaires consisting of the tests described above in print or online format, which were later collected and processed. The research participants were at liberty to fill in the questionnaire in any convenient order as this did not affect the research results - the coverage of each test does not overlap with the others. Two weeks allotted to fill out the tests, during which time all tests were distributed, completed by participants in printed or electronic form, returned, verified and found to be valid.

\section{Data analysis}

Participants completed two types of questionnaires on two tests: The Career Anchor methodology (Schein \& Maanen, 2013) and the self-attitude questionnaire (Stolin \& Pantileev, 1988). In what follows, descriptive statistics are used, obtained as a result of analyzing the distribution of participants' answers in these two tests. Mann Whitney U test was used to compare the indicators of career orientations in the 2 groups of respondents. Based on the results, statistically significant deviations in the statistics of individual indicators of career orientations and self-attitude indicators are determined, the value of which obtained in the first of the described tests. Thus, significant differences established between the indicators of the experimental and control groups, which allow accepting or rejecting the research hypothesis.

\section{Instruments}

The results were processed based on the methods of mathematical data analysis. Statistical processing was performed in SPSS v22.0. The data were visualized in MS Excel 2013.

\section{Research limitations}

The research sample was not differentiated by gender, social divergence, age, and other indicators, which could provide additional important information about the subject of the study. The study involved only two Russian universities; therefore, the results of the research should be carefully extrapolated into other educational institutions.

\section{Ethical issues}

All study participants were guaranteed anonymity; they received a detailed explanation of the purpose and method of conducting experiments and tests. No personal data were collected or used.

\section{FINDINGS}

According to the results of the study on the methodology for determining the level of self-efficacy, it can be concluded that students generally give an average assessment of their potential in the sphere of substantive work and communication. The indicators of 
students with a low level of self-efficacy demonstrate their pessimistic attitude towards their own actions and achievements.

When investigating the intensity of career orientations of college students, we consider subgroups with an average and low level of self-efficacy in the sphere of substantive work.

Figure 1 graphically presents descriptive statistics for The Career Anchor methodology test. The study results showed that the indicator of professional competence is identical in the two groups (57\% in Group 1 and 58\% in Group 2). Thus, both groups of respondents with different levels of self-efficacy strive to find their vocational aptitude, want to become professionals, and achieve success in the professional sphere.

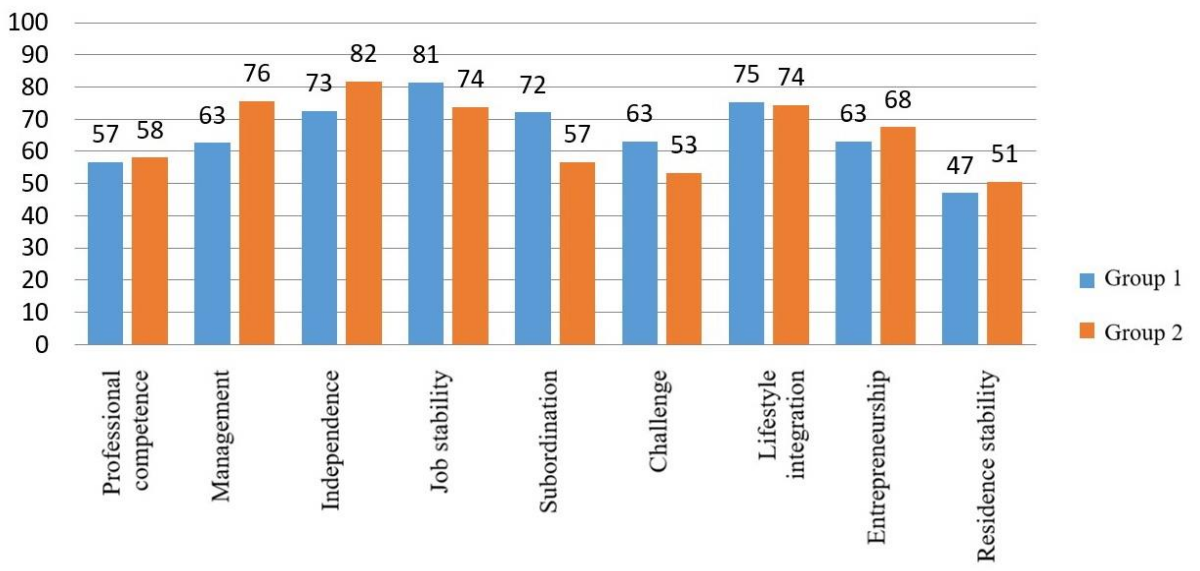

Figure 1

The intensity of indicators based on the Career Anchor methodology developed by Schein and Maanen (2013), in \% (self-efficacy in the sphere of substantive activity).

The management indicator in Group 1 and Group 2 is $63 \%$ and $76 \%$, respectively. Due to the fact that Group 1 is much larger than Group 2, it can be argued that the respondents with an average level of self-efficacy have a better ability to manage. Thus, the students of Group 1 are ready to make more efforts to perform complex tasks, for example to manage people and projects, as well as to take full responsibility for the final result. The intensity of the management indicator in the group with a low level of selfefficacy demonstrates that the students in this group are ready to take responsibility for the whole team when needed. Basically, they prefer the subordinate role.

The two groups of respondents demonstrated a high level of independence $(73 \%$ and $82 \%$, respectively). Therefore, the students of both groups would like to work in a company that could provide them with a sufficient degree of freedom. They believe that the most important task of further career development is to get an opportunity to work independently following one's own pattern. A strict company policy is more likely to 
alienate respondents, and despite the obviously attractive vacancy, the choice will be made in favor of the company providing enough freedom.

The results of the study also revealed high job stability indicators in the two groups $(81 \%$ and $74 \%)$. Thus, the majority of the students surveyed are in want of security and reliable earnings for a long time. It is most likely that short-term projects and start-up companies do not attract them. They seek the social guarantees that the employer can offer, and, as a rule, their workplace choice is directly associated with a long-term employment contract and a stable position of the company in the market.

The residence stability indicator was $47 \%$ and $51 \%$ in the group of students with an average self-efficacy level and a group of students with a low one, respectively. Based on this fact, we can conclude that for half of the students surveyed, moving to another city is unacceptable. They find it more important to live in one place rather than to get a promotion or a new position in a new area. Frequent business trips are a negative factor for them when considering a vacancy.

The group of students with an average level of self-efficacy demonstrated their willingness to be subordinates $(72 \%)$. Thus, these students are more focused on bringing benefits to people and society. The students find it important to observe the results of their work both in the context of being recognized and receiving some remuneration. These students are also more likely to refuse a job in a company that is hostile to their goals and values. In the group with a low level of self-efficacy, the indicator is $57 \%$. This demonstrates that such students rarely work for the good of society and have their own selfish goals.

The challenge indicator turned out to be high in the group of students with an average level of self-efficacy $(63 \%)$. As a rule, such students enjoy overcoming obstacles and dealing with challenging problems. For some people the challenge is a more difficult task while others prefer competition. Such students appreciate it when they are constantly involved in the solution of difficult problems or in a competitive situation. The indicator in Group 2 is slightly lower (53\%). This shows that the respondents are more focused on performing professional activities following the instructions, as well as a friendly interaction with the colleagues rather than a competition with them.

Both groups of students demonstrated a high percentage of lifestyle integration readiness (75\% and $74 \%$ ). Based on this, it can be assumed that such students will be attracted to career development only if it does not disrupt their lifestyle and environment. These students believe that everything should be balanced: career, family, personal interests, free time, etc. As a rule, they are not ready to make a sacrifice for the sake of career development.

The entrepreneurship indicator is $54 \%$ and $68 \%$ in the group of students with an average level of self-efficacy and in the group of respondents with a low one, respectively. It can be assumed that students with an average level of self-efficacy are most likely to give a more adequate assessment of their capabilities compared to the students with low selfefficacy. However, Group 1 considers creating something new as a waste of personal time. Group 2 believes that the career development peak is the creation of one's own 
business. They do not want to work for companies and think that they can set up their own company.

According to the results of the study based on the career anchor methodology (Schein \& Maanen, 2013), we can conclude that in the groups of students with different levels of self-efficacy, there was no lack of the indicators of career orientations. The group of students with an average level of self-efficacy is characterized by a high indicator of job stability and a low indicator of residence stability. The group of respondents with a low level of self-efficacy demonstrated a high independence indicator and low challenge and residence stability indicators.

The study relied on the self-attitude questionnaire methodology (Stolin \& Pantileev, 1988) in order to determine the level of self-attitude, as well as the intensity of the selfefficacy components. The respondents were divided into two groups: students with an average level of self-efficacy and students with a low one. The results are described in Figure 2, which shows the intensity of each component observed in Group 1 and Group 2 .

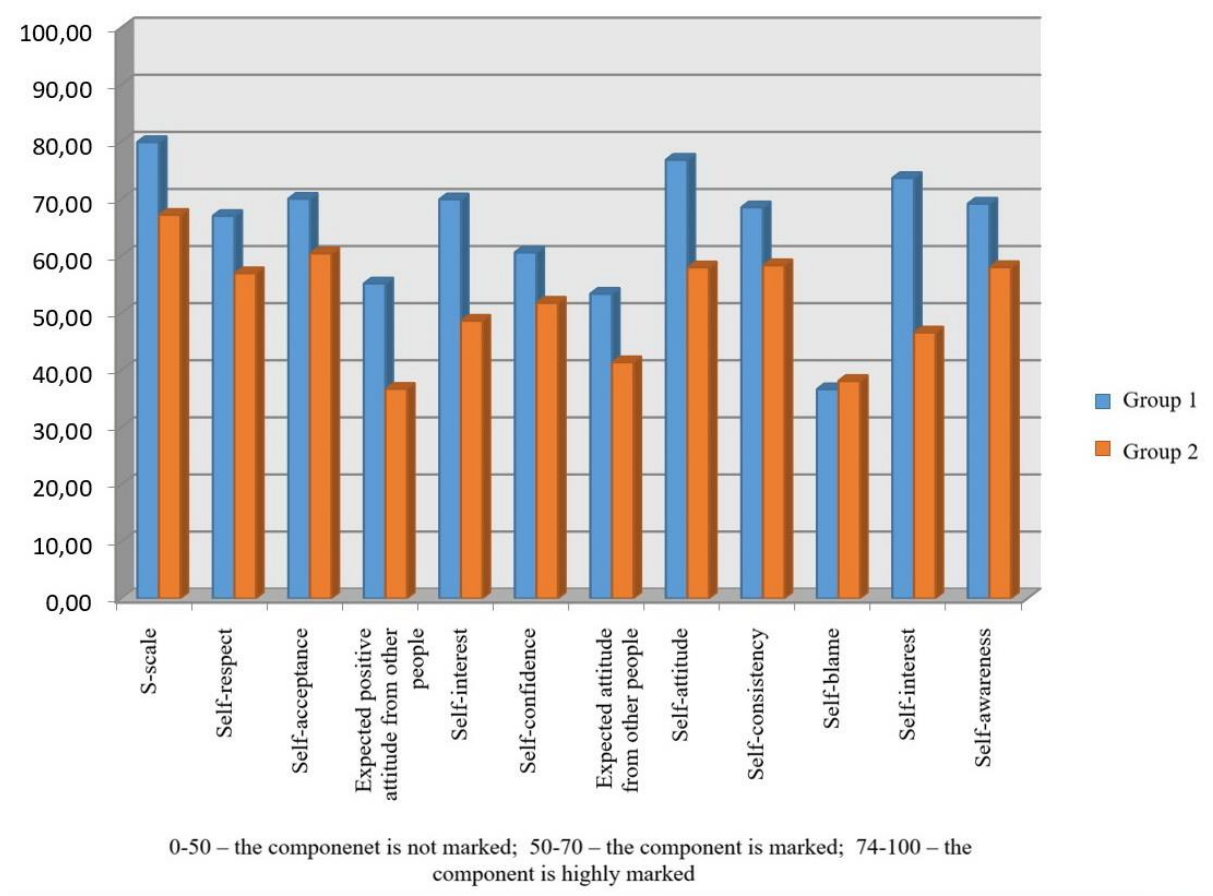

Figure 2

The intensity of indicators according to the self-attitude questionnaire methodology (Stolin \& Pantileev, 1998).

Thus, the results of the application of the self-attitude questionnaire methodology show that Group 1 demonstrates a stronger intensity of all indicators described. 
In Group 1 and Group 2, the values of the global self-attitude indicator dominate the first five indicators. This shows us that the respondents are characterized by an internal undifferentiated feeling of "for" and "against" themselves. The respondents with a low level of self-efficacy demonstrated a normal level of global self-attitude in contrast to the students with an average level of self-efficacy, who have a greater intensity of the component.

Let us consider the results of the group of students with an average level of self-efficacy (Group 1). Figure 2 shows that the group of students with an average level of selfefficacy demonstrates high indicators of self-acceptance and self-interest. The selfacceptance indicator reflects the items related to self-acceptance and self-blame that involve friendliness and hostility to one's own self. This group is characterized by strong self-acceptance; self-blame has not been revealed. Thus, the respondents of the first group generally and substantially approve of themselves, trust themselves, and give a positive assessment of their personality. The high self-interest indicators reflect a degree of closeness to oneself. Therefore, these students have a great interest in their thoughts and feelings and are confident that other people can be interested in them.

We can also highlight the intensity of self-respect. The self-respect scale reflects items related to self-management, self-awareness, and self-confidence. In this group of students, the three items were found to be at the average level. This shows us that the respondents are confident in themselves and their strengths, energetic and independent enough; they know how to assess their capabilities and understand themselves, are selfconsistent, and can control their life.

In the group of respondents with an average level of self-efficacy, the indicator of the expected attitude from others is the lowest. This shows that these students do not expect a positive or negative attitude from other people; nevertheless, they reflect on this topic, otherwise, the indicator would not have been identified.

Let us consider the results of the second group of students with a low level of selfefficacy. The respondents did not demonstrate any degree of the expected attitude from others. Thus, they do not have reflections on the attitude of other people to them. Based on the close to high indicator of self-acceptance, these students approve of themselves and their actions, as well as give themselves a positive assessment. We made the conclusion based on the fact that the indicator of self-acceptance is rather marked. The self-blame indicator was not identified.

The intensity of the self-respect indicator tells us that the totality of self-management, self-awareness and self-confidence in this group of students confirms self-confidence, energetic attitude, and independence of students. The respondents understand themselves well and can assess their capabilities.

The self-interest indicator in the second group of students with a low level of selfefficacy was not identified. Thus, the respondents are not close enough to themselves; they have no interest in their thoughts and feelings, and consider them uninteresting to other people. The results of the research based on this methodology allow us to conclude 
that in Group 1 and Group 2, the values of the global self-attitude indicator dominate the first five indicators.

In the group of students with an average level of self-efficacy, a high intensity of all indicators was observed, which is not the case for the second group of students with a low level of self-efficacy. In this group, there is no expectation of a positive attitude from others. This is explained by the high intensity of the self-acceptance indicator. The self-acceptance indicator reflects the items related to self-acceptance and self-blame that involve friendliness and hostility to one's own self. This group is characterized by strong self-acceptance; self-blame has not been revealed. This shows us that the respondents approve of themselves as a whole, trust themselves, give a positive assessment of their personality and are confident that others treat them in the same way as they do.

The Mann Whitney U test was used to compare the indicators of career orientations in the 2 groups of respondents. The criterion selection was based on the analysis of the skewness index of kurtosis, which does not correspond to the normal type of distribution. The results are presented in Table 1.

Table 1

The results of the comparative analysis of career orientations and self-attitude indicators in the groups according to the level of self-efficacy in the sphere of substantive activity

\begin{tabular}{lllll}
\hline \multirow{2}{*}{ Indicator } & \multirow{2}{*}{ U-criterion } & Significance & \multicolumn{2}{l}{ Midrank } \\
\cline { 3 - 5 } & & value & 1 & 2 \\
\hline Lifestyle integration & 103.500 & 0.087 & 33.56 & 23.96 \\
\hline Entrepreneurship & 86.500 & 0.031 & 35.69 & 23.56 \\
\hline Scale S - Global self-attitude & 106.000 & 0.099 & 33.25 & 24.02 \\
\hline Self-respect & 88.500 & 0.034 & 35.44 & 23.61 \\
\hline Self-acceptance & 102.500 & 0.081 & 33.69 & 23.94 \\
\hline Self-management & 79.500 & 0.014 & 36.56 & 23.39 \\
\hline Self-blame & 104.500 & 0.084 & 17.56 & 27.01 \\
\hline Self-awareness & 103.000 & 0.076 & 33.63 & 23.95 \\
\hline
\end{tabular}

We revealed a difference between the groups of students with an average and low level of self-efficacy in terms of the lifestyle integration indicator $(U=103.5 ; p=0.087)$. This can be explained by the fact that students with an average level of self-efficacy more rationally plan their lives. These students believe that everything should be balanced: career, family, personal interests, free time, etc. The respondents uniformly distribute their strengths and capabilities unlike students with a low level of selfefficacy.

There are also significant differences between the groups of students with an average and low level of self-efficacy in terms of the entrepreneurship indicator $(\mathrm{U}=86.5 ; \mathrm{p}=$ 0.031 ); the indicator is higher in the group of students with a low level of self-efficacy. Students are willing and ready to implement their ideas but they do not take any action.

The comparative analysis of the results of the groups of students with different levels of self-efficacy in the field of substantive activity revealed a number of differences in terms of self-attitude indicators as self-efficacy components. 
We found the differences in terms of the global self-attitude indicator ( $U=106.0$; $\mathrm{p}=0.099$ ). Students with an average level of self-efficacy in substantive activity have higher self-attitude indicators. Therefore, the respondents accept themselves along with their merits and demerits and generally feel that they are interesting people.

There are also noticable differences in the context of the self-respect indicator between the students with an average and low level of self-efficacy ( $U=88.5 ; p=0.034)$. The Group 1 respondents are more confident in themselves and their strengths, are quite independent, know how to assess their capabilities and understand themselves, can control their life.

There are also differences in terms of self-acceptance $(U=102.5$; $p=0.081)$, selfmanagement $(U=79.5 ; p=0.014)$ and self-awareness $(U=103.0 ; p=0.076)$. This shows that students with an average level of self-efficacy generally trust and approve of themselves. They listen to their thoughts and feelings, and in case of failure in their activities, first of all they try to consider their internal reasons. Such students are characterized by self-confidence, energetic attitude and independence, as well as an objective assessment of their capabilities.

We found differences in terms of the self-blame indicator $(U=104.5 ; p=0.084)$, which show us that the students with a low level of self-efficacy are prone to self-blame. Such students are characterized by irritation and self-contempt, self-judgment, and a pessimistic attitude towards their own actions and achievements (Table 2).

Table 2

The results of the comparative analysis of career orientations in the groups according to the level of self-efficacy in the sphere of interpersonal communication

\begin{tabular}{lllll}
\hline \multirow{2}{*}{ Indicator } & \multirow{2}{*}{ U-criterion } & \multirow{2}{*}{$\begin{array}{l}\text { Significance } \\
\text { value }\end{array}$} & \multicolumn{2}{l}{ Midrank } \\
\cline { 4 - 5 } & & 0.092 & 1 & 2 \\
\hline Independence & 164.500 & 0.042 & 31.35 & 23.45 \\
\hline Job stability & 149.500 & 0.011 & 33.50 & 27.96 \\
\hline Self-management & 131.000 & & 22.54 \\
\hline
\end{tabular}

We also found the differences between the groups of students with an average and low level of self-efficacy in the field of interpersonal communication. The first difference is related to the independence indicator $(\mathrm{U}=164.5$; $\mathrm{p}=0.092)$. This demonstrates that students with an average level of self-efficacy in communication will feel comfortable in a workplace that does not have strict rules and allows free communication during working hours.

There are significant differences in terms of job stability $(\mathrm{U}=142.5 ; \mathrm{p}=0.042)$. Thus, students with a low level of self-efficacy in the field of communication can work in one organization for quite a long time. They are not characterized by frequent change of workplace as they experience certain difficulties in communication.

We also found significant differences in the context of self-management ( $U=131.0$; $\mathrm{p}=0.011$ ). Students with an average level of self-efficacy are more prone to self- 
management. They are characterized by the ability to manage their behavior and actions. They respect themselves, control and harmonize their lives.

Thus, the hypothesis about the differences in career orientations between the groups of students with different levels of self-efficacy was partially confirmed by the comparative analysis.

\section{DISCUSSION}

Various studies on self-efficacy revealed rather similar results; most of them confirm, for example, the relationship between self-efficacy and independent choice, selfmanagement, the desire for a proactive lifestyle (Ebner et al., 2018; Mesterova et al., 2015; Ozyilmaz et al., 2018). There is a study presented evidences of the mediating role of self-efficacy in building of framework of self-management and coping with various problems (Ebner et al., 2018). The other side is represented by students who are prone to self-blame and pessimism. They also demonstrate low levels of social skills, and most often have low level of independence, require or expect help from other students or teachers (Peiffer et al., 2020).

The comparative analysis of possible career orientations in relation to self-management and self-efficacy is unique for the present paper as we have not managed to find such an approach in other studies (Lent et al., 2017). At the same time, the factor analysis and other methodologies for studying self-efficacy indirectly demonstrate that there is a correlation between this parameter and the choice of profession or lifestyle (Bravo et al., 2017; Cybal-Michalska, 2016). Most often, the research concludes that self-management and self-confidence are the key self-efficacy factors that contribute to entrepreneurship, business improvement or faster career development (Peiffer et al., 2020).

The results of our research are a bit different from the findings of other studies in terms of the fact that people with a low level of self-efficacy demonstrate increased selfacceptance and have little interest in what other people think of them. In fact, the increased importance of social assessment is a factor that suppresses independence and correlates well with low indicators of social skills and poor academic performance (Evplova, 2019; Li et al., 2019). This result is probably associated with the ability to make social connections and networks of trust, which are decisive factors in most career activities indicated in Table 1 as they require high self-efficacy. In this case, the result is easily interpreted in accordance with the findings of other well-known studies (Lepri et al., 2016).

An important additional factor that has not been directly considered in the study but is associated with the factors reflected in the questionnaires includes energetic and positive attitude, and a strong psychophysiological ability to take action. An important selfefficacy aspect is the absence or low level of depression, psychosomatic and behavioral disorders. Personal leadership, the ability to take responsibility, a positive assessment of one's own personality and the ability to cope with challenges increase the number of psychophysical capabilities of a person. This contributes to higher productivity and an active manifestation of abilities and talents, and, accordingly, to better performance (Holland, 2016; Johnson et al., 2018; Schein \& Schein, 2018). 
An average and low levels of self-efficacy are associated with a stereotypical lifestyle and the unwillingness to change. The same findings are described in other studies. For example, the development of certain technical skills of planning and self-management is not associated with the rigidity of behavior, as it might seem, but, on the contrary, with the ability to change the way of life, circumstances, career and achieve goals. In general, success in the achievement of goals is closely related to the willingness to change the way of life (Salame \& Thompson, 2020). A number of researchers believe that the mobility of thought, the ability to change the point of view and accept the opinion of others are the qualities significantly associated, on the one hand, with the entrepreneurial activity, and on the other, with a higher level of personal achievements in life (Komarraju et al., 2014 Setiawati et al., 2017).

\section{CONCLUSION}

The theoretical analysis showed that in the scientific literature there are different approaches to the study of the phenomenon of personality predictors of the career orientations of college students. In the present paper, self-efficacy is described as the degree of the person's belief that they are able to carry out activities. The study was conducted on the representative sample of 558 third-year students of the Ural State College named after I. Polzunov (Ekaterinburg) of 18 to 20 years old. They were divided into two groups, according to the level of self-efficacy, determined by the test of self-efficacy by James E. Maddux and D. Scheer. The study used also two base tests, The Career Anchor methodology (Schein \& Maanen, 2013) and the self-attitude questionnaire (Stolin \& Pantileev, 1988); the statistic values obtained for the indicators of career orientations were analyzed by The Mann Whitney U test. The study hypothesis about the absence of correlation between career orientations and self-efficacy and the absence of differences between the career orientations of students with different levels of self-efficacy were rejected.

The results of the study on the methodology for determining the level of self-efficacy showed that the students surveyed do not have a high level of self-efficacy. The respondents were divided into two groups: students with an average level of self-efficacy and students with a low one. The Career Anchor methodology demonstrated the high intensity of all indicators of career orientations in the groups of students with different levels of self-efficacy. The group of students with an average level of self-efficacy is characterized by a high indicator of job stability and a low indicator of residence stability. The group of respondents with a low level of self-efficacy demonstrated a high independence indicator and low challenge and residence stability indicators. The selfattitude questionnaire results showed that in Group 1 and Group 2, the values of the global self-attitude indicator dominate the first five indicators. In the group of students with an average level of self-efficacy, a high intensity of all indicators was observed, which is not the case for the second group of students with a low level of self-efficacy. In this group, there is no expectation of a positive attitude from others; and it is characterized by strong self-acceptance. According to the results of the comparative analysis, the respondents with an average level of self-efficacy in the sphere of substantive activity are more likely to integrate lifestyle, and in the sphere of 
interpersonal communication, they are prone to independence. Students with a low level of self-efficacy in the sphere of substantive activity have a stronger tendency to conduct entrepreneurial activities and those with a low level of self-efficacy in the field of communication highly appreciate job stability. Thus, the hypothesis about the differences in career orientations between the groups of students with different levels of self-efficacy was partially confirmed by the comparative analysis. The correlation analysis showed that in the total sample there are 13 relationships between career orientations and the levels and components of self-efficacy. We revealed a reliable and strong correlation between self-management and self-efficacy in the field of interpersonal communication, self-blame and self-management, self-awareness and professional competence.

The research results confirm the need to create conditions for improving self-efficacy in order to develop career orientations in college students.

\section{REFERENCES}

Akosah-Twumasi, P., Emeto, T. I., Lindsay, D., Tsey, K., \& Malau-Aduli, B. S. (2018). A systematic review of factors that influence youths career choices-the role of culture. Frontiers in Education, 3, 58.

Bandura, A., \& Hall, P. (2018). Albert Bandura and social learning theory. In Learning theories for early years practice (pp. 63-65). Sage.

Boyarintseva, A. V. (2003). Self-efficacy test. In Psychology of the development of a competitive personality (pp. 217-219). Moscow: Moscow psychological and social institute; city of Voronezh, Russian Federation: MODEK.

Bravo, J., Seibert, S. E., Kraimer, M. L., Wayne, S. J., \& Liden, R. C. (2017). Measuring career orientations in the era of the boundaryless career. Journal of Career Assessment, 25(3), 502-525.

Cybal-Michalska, A. (2016). Proactive Behavioral Orientation of a Subject as a Process of Investing in Career Capital in the World of "Boundaryless Careers". In Advances in Physical Ergonomics and Human Factors (pp. 931-942). Springer, Cham.

Ebner, K., Schulte, E. M., Soucek, R., \& Kauffeld, S. (2018). Coaching as stressmanagement intervention: The mediating role of self-efficacy in a framework of selfmanagement and coping. International Journal of Stress Management, 25(3), 209-233.

Evplova, E. V. (2019). Social characteristics of personal and corporate competitiveness of future specialists: results of sociological research. The Education and Science Journal, 21(2), 132-154.

Falco, L. D., \& Summers, J. J. (2019). Improving career decision self-efficacy and STEM self-efficacy in high school girls: Evaluation of an intervention. Journal of Career Development, 46(1), 62-76. 
Garanina, Z. G., Balyaev, S. I., \& Ionova, M. S. (2019). The Role of Self-Attitude in the Personal and Professional Development of High School Students. The Education and science journal, 21(1), 82-96.

Holland, J. L. (2016). Making vocational choices: A theory of careers. Englewood Cliffs, N.J.: Prentice-Hall.

Johnson, J., Irizarry, M., Nguyen, N., \& Maloney, P. (2018). Part 1: Foundational theories of human motivation. Motivation 101: A Guide for Public Servants. University of Central Florida. Retrieved 7 January, 2021 from https://stars.library.ucf.edu/motivationforpublicservants/1/

Koch, I. A., \& Orlov, B. A. (2020). Values and professional identity of student-age population. The Education and Science Journal, 22(2), 143-170.

Komarraju, M., Swanson, J., \& Nadler, D. (2014). Increased career self-efficacy predicts college students' motivation, and course and major satisfaction. Journal of Career Assessment, 22(3), 420-432.

Lent, R. W., Ireland, G. W., Penn, L. T., Morris, T. R., \& Sappington, R. (2017). Sources of self-efficacy and outcome expectations for career exploration and decisionmaking: A test of the social cognitive model of career self-management. Journal of Vocational Behavior, 99, 107-117.

Leontyev, D. A. (2016). The Concept of Motive in AN Leontyev, and the Problem of Quality of Motivation. Bulletin of Moscow University. Ser. Psychology, 2, 3-18.

Lepri, B., Staiano, J., Shmueli, E., Pianesi, F., \& Pentland, A. (2016). The role of personality in shaping social networks and mediating behavioral change. User Modeling and User-Adapted Interaction, 26(2-3), 143-175.

Li, H., Ngo, H. Y., \& Cheung, F. (2019). Linking protean career orientation and career decidedness: The mediating role of career decision self-efficacy. Journal of Vocational Behavior, 115, 103322.

Lippke, S. (2020). Self-efficacy theory. In Encyclopedia of personality and individual differences (pp. 4722-4727). Springer, Cham.

Maree, K. (2017). The psychology of career adaptability, career resilience, and employability: A broad overview. In Psychology of career adaptability, employability and resilience (pp. 3-11). Springer, Cham.

Mesterova, J., Procházka, J., Vaculík, M., \& Smutny, P. (2015). Relationship between self-efficacy, transformational leadership and leader effectiveness. Journal of Advanced Management Science, 3(2), 109-122.

Olivier, E., Archambault, I., De Clercq, M., \& Galand, B. (2019). Student self-efficacy, classroom engagement, and academic achievement: Comparing three theoretical frameworks. Journal of youth and adolescence, 48(2), 326-340. 
Ozyilmaz, A., Erdogan, B., \& Karaeminogullari, A. (2018). Trust in organization as a moderator of the relationship between self-efficacy and workplace outcomes: A social cognitive theory-based examination. Journal of Occupational and Organizational Psychology, 91(1), 181-204.

Panadero, E., Jonsson, A., \& Botella, J. (2017). Effects of self-assessment on selfregulated learning and self-efficacy: Four meta-analyses. Educational Research Review, $22,74-98$.

Peiffer, H., Ellwart, T., \& Preckel, F. (2020). Ability self-concept and self-efficacy in higher education: An empirical differentiation based on their factorial structure. PloS One, 15(7), e0234604.

Salame, I. I., \& Thompson, A. (2020). Students' views on strategic note-taking and its impact on performance, achievement, and learning. International Journal of Instruction, 13(2), 1-16.

Schein E. H., \& Maanen, J. (2013). Career anchors: the changing nature of work and careers. San Francisco: Wiley.

Schein, E. H., \& Schein, P. A. (2018). Humble leadership: The power of relationships, openness, and trust. Berrett-Koehler Publishers.

Setiawati, F. A., Ayriza, Y., Retnowati, E., \& Amelia, R. N. (2017). The response patterns of the career interest instrument based on Holland's theory. ANIMA Indonesian Psychological Journal, 32(3), 128-147.

Stolin, V. V., \& Pantileev, S. R. (1998). Self-attitude questionnaire. In Psychodiagnostics manual: Psychodiagnostic materials (pp. 123-130). Moscow: MSU Publishing House.

Suryadi, B. (2020). The Influence of Adolescent-Parent Career Congruence and Counselor Roles in Vocational Guidance on the Career Orientation of Students. International Journal of Instruction, 13(2), 45-60.

Zhu, J., Lee, B. H., Diaz, D., \& Flores, L. Y. (2019). Evaluating the scholarly impact of vocational research with diverse racial/ethnic groups: 1969-2017. Journal of Career Development, 0894845319846423. 